\title{
ESTIMATES FOR BERNSTEIN TYPE OPERATORS
}

\section{ZOLTÁN FinTA}

Abstract. We prove the existence of a sequence of linear positive bounded polynomial operators on $C[0,1]$ which preserve the functions $e_{0}(x)=1$ and $e_{2}(x)=x^{2}$. An extremal property and quantitative estimates are given.

Mathematics subject classification (2010): 41A25, 41A36.

Keywords and phrases: Bernstein operators, polynomial bounded positive operators, modulus of continuity, ordered normed spaces.

\section{REFERENCES}

[1] H. Berens And R. A. DeVore, A characterization of Bernstein polynomials, In: Approximation Theory III (edited by E. W. Cheney), Academic Press, New York, 1980, pp. 213-219.

[2] J. Bustamante And J. M. Quesada, On an extremal relation of Bernstein operators, J. Approx. Theory, 141 (2006), 214-215.

[3] R. A. DeVore and G. G. Lorentz, Constructive Approximation, Springer Verlag, Berlin, 1993.

[4] M. FeLten, Local and global approximation theorems for positive linear operators, J. Approx. Theory, 94 (1998), 396-419.

[5] I. Gavrea AND D. H. Mache, Generalization of Bernstein-type approximation methods, In: Approximation Theory, Proc. IDoMAT 95 (M. W. Müller, M. Felten and D. H. Mache, Eds.) Mathematical Research, Vol. 86, Akademie Verlag, Berlin, 1995, pp. 115-126.

[6] H. Gonska And P. Piţul, Remarks on an article of J. P. King, Comment. Math. Univ. Carolinae, 46 (2005), 645-652.

[7] J. P. KING, Positive linear operators which preserve $x^{2}$, Acta Math. Hungar., 99, 3 (2003), 203-208.

[8] G. MARInescu, Normed Linear Spaces, Academic Press, Bucharest, 1956 (in Romanian). 